International Journal of

Health, Medicine and

Nursing Practice

(IJHMNP)

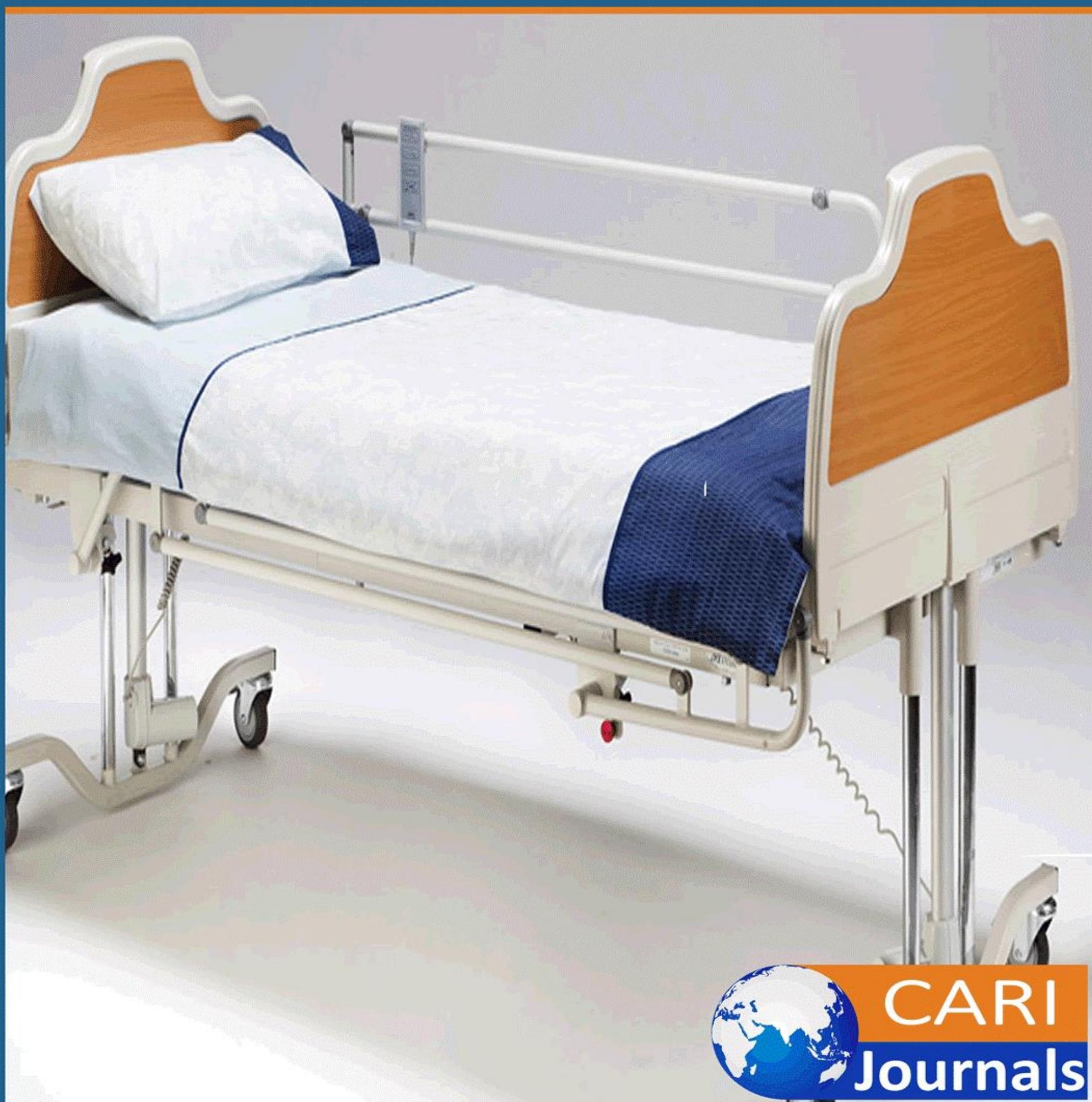


International Journal of Health, Medicine and Nursing Practice

ISSN 2710-1150 (Online)

Vol. 3, Issue No. 1, pp 44- 61, 2021

$\underline{\text { www.carijournals.org }}$

\title{
Knowledge, Attitude, and Practices towards Physical Assessment of Critically Ill Patients among Nurses Working in Intensive Care Unit: A Cross-Sectional Study in Lahore, Pakistan
}

\author{
$1 *$ Muhammad Saghir \\ BSN (Post RN), Lahore School of Nursing, The University of Lahore \\ *Corresponding Author E-mail: muhammadsaghir226@gmail.com \\ ${ }^{2}$ Muhammad Hussain \\ Associate professor Lahore School of Nursing, The University of Lahore, PhD Scholar,_Master \\ of Science in Nursing \\ ${ }^{3}$ Kousar Perveen \\ Assistant Professor, Lahore School of Nursing, The University of Lahore, Master of Science in \\ Nursing \\ ${ }^{4}$ Muhammad Afzal \\ Principal, Lahore School of Nursing, The University of Lahore, Master of Science in Nursing \\ ${ }^{5}$ Maliha Shoukat \\ BSN (Post RN), Lahore School of Nursing, The University of Lahore
}

\begin{abstract}
Purpose: The purpose of the study to examine nurses' knowledge, attitudes, and practices towards physical assessment of critically ill patients in Tertiary Care Hospital, Lahore Pakistan.

Methodology: The cross-sectional study was performed. A well-designed questionnaire was used to observe responses. Statistical Package for the Social Sciences (SPSS) version 25 was used to analyze the data. For the analysis, descriptive statistics of demographic data were used, meaning standard deviation and frequency. The Pearson correlation test was used to measure the correlation between knowledge, attitude, and practice towards physical assessment of critically ill patients. The study results display in tables and charts. Pearson correlation at $\mathrm{p}<0.05$ consider as significant.

Findings: The study was carried out to assess the knowledge, attitude, and practice among intensive care unit nurses towards physical assessment of critically sick patients in Tertiary Care Hospital Lahore, Pakistan. In this study, around 57.2\% of nurses had good knowledge, 59.4\% positive attitude, and $68.1 \%$ good practice towards critical ill patient's physical assessment

Unique contribution to theory, practice and policy: This study provide the opportunity to the nurses better to enhance their level of knowledge and skill of practice on physical assessment. Nurses, who had better knowledge and skill, should also teach their respective colleagues.
\end{abstract}

Keywords: Knowledge, Attitude, Practice, Intensive Care Unit, Nurses, Physical Assessment. 
International Journal of Health, Medicine and Nursing Practice

ISSN 2710-1150 (Online)

Vol. 3, Issue No. 1, pp 44- 61, 2021

$\underline{\text { www.carijournals.org }}$

\section{INTRODUCTION}

Physical assessment is the process of getting information and evaluating goals through the use of inspection, palpation, percussion, and auscultation. The information obtained must be thoughtfully integrated with the pathophysiology and patient's history. In addition, physical assessment provides the basis for planning and implementing nursing interventions that enhance the competent and safe care of patients. Internationally, nurses perform frequently physical assessment of critical ill patients in intensive care unit that helps in good practices and early recovery of patient from intensive care unit. In Pakistan, patients' ratio high for nurses as compare to developed countries. Patients have a long stay in intensive care unit and slow recoveries that can be due poor physical assessment techniques. Physical assessment has been an integral part of the nursing field for the last 20 years (Alamri \& Almazan, 2018).

Physical examination is considered an important role of nursing professionals, who are asked to make an accurate physical diagnosis (Cicolini et al., 2015). Physical examination serves for different purposes, such as gathering data about the patient's overall health status and obtaining additional information about the signs and symptoms reported by the patient. The most common form of diagnosis extends from the head to the feet and the physical system. In the intensive care unit (ICU), patients need special consideration and supervision along with physical examinations (Meurier, Brown, \& Crouch, 2016). To examine critically ill patients in the intensive care unit, this requires skilled practices, knowledge of patient care and a positive attitude. Physical diagnosis is the process of identifying the real and potential problems of individual patients. However, many literature reviews show that most nurses do not consider physical examination their job (Liyew, Dejen Tilahun, \& Kassew, 2020).

Physical assessment is an important skill for nurses, as it is an integral part of the first stage of the nursing process, provides a framework for promoting fitness, and is common for interacting with other health professionals. This is often a prerequisite for graduate study and is a basic skill for students moving to advanced training areas. This is a mandatory qualification for registered nurses (Kutah, 2021). Systematic physical examination has become a "sacred cow" in nursing profession because practically it diverts the nurse's attention from the patient's experience of the disease (Tan et al., 2021). Nurses are an integral part of the multi-disciplinary health care team. In the intensive care unit, nurses have the responsibility and privilege to perform a referral physical assessment for each of their patients in order to provide an important opportunity for their care to meet the needs of patients. Be suitable to meet. The focused physical examination will allow the nurse to detect clear and subtle variations in the health status of the patients. It depends on the skill level of the dependent and the knowledge of normal anatomy and physiology. Regular physical diagnosis remains the most important component of patient care within a time that is practical and should never be excluded due to time constraints (Birks, Cant, James, Chung, \& Davis, 2013)

The nurses who have advanced diagnostic skills, advanced training skills, and those who are passionate about using technology are most successful nurses in advanced era. Nurses should work independently in using health assessment skills and enjoy self-confidence to achieve nursing goals. Nurses usually live continuously in complex medical situations that need advanced testing skills. Holistic Nursing Care requires patient design and design offerings based on information gained 
International Journal of Health, Medicine and Nursing Practice ISSN 2710-1150 (Online)

Vol. 3, Issue No. 1, pp 44- 61, 2021

$\underline{\text { www.carijournals.org }}$

from physical examinations, discussions and interviews on patient history (Khoran, Alhani, Hajizadeh, \& Sciences, 2018). Physical assessment techniques related to the respiratory system has been found to be one of the basic techniques. It was established that basic techniques of physical examination of nurses mainly included vital signs (Osborne, Douglas, Reid, Jones, \& Gardner, 2015)

Knowledge, attitude and practice studies are a survey that focuses on collecting population data on what is known, considered and implemented in response to a particular topic or situation. That is why knowledge, attitude and practical studies are one of the most widely used survey methods in the social health sciences. Knowledge is public information about a particular health issue or topic. Knowledge is created through interaction with one's environment where individuals develop their understanding of the world through their own experience. Human knowledge usually comes with the process of communication. Attitude is a tendency or prediction that reacts negatively or positively to a particular object, idea, person, or situation (Liyew, Dejen Tilahun, \& Kassew, 2020).

Attitude also influences an individual's choice of specific reactions, and reactions to challenges, rewards, etc. Knowing something about a person from an individual's cognitive aspect means that the related component represents an individual's emotions. The way people act for the situation and individual motivation. Sociologists consider behavior to be an element of perception, love and behavior. Comprehensive attitudes are more stable and generally owned by owners, and as a result, it is more difficult when it is not impossible to influence them than in inappropriate attitudes. Individual behavior can be predicted by the strength of their attitude and consistency. Thus, any intervention aimed at changing an individual's behavior should initially have enough information about his or her behavior and later use the methods that can help change the behavior. Knowledge does not necessarily affect an individual's behavior. People are particularly aware of risk-related behavior but still act on it (Nigussie, 2018). Practices in healthcare refer to precise actions or prevention and treatment in response to a particular medical condition. In society, individuals behave differently in their own context (Nigussie, 2018).

Physical examination is one of the essential functions of nursing professionals, who are requested to make an accurate and complete physical assessment (Cicolini et al., 2015). In intensive care units, patients often experience long-term immobilization which in turn contributes to neuromuscular complications. Registered nurses and midwives play an important role in determining the risk of deteriorating patients through ongoing diagnosis and action in response to changing health conditions. Nevertheless, the evidence suggests that clinical malformations are often overlooked in hospitalized patients. Although much attention has been paid to early warning and rapid response systems, little research has examined factors related to physical examination skills (Osborne et al., 2015). The aim of this study is to assess the knowledge, attitude and practice of nursing professionals working in the intensive care unit regarding the physical examination. 


\section{Statement of the Problem}

Nursing is an essential profession of service within the healthcare system. An increasing need for a physical examination for a critically ill patient in an intensive care unit demands high-level specialist care. All nurses' care will depend on the results of the physical assessment. There is growing evidence that hospitalized patients are at high risk of medical malpractice, partly due to inadequate knowledge of the physical assessment and the behavior of nurses leading to increased mortality in the intensive care unit. However, various literatures report that $30 \%$ to $40 \%$ patients do not get health related care based on advanced knowledge and $20 \%$ to $25 \%$ patients receive unnecessary care due to physical examination. Since there is no study in Tertiary Care Hospital. Therefore, in order to identify the current knowledge of Tertiary Care Hospital Lahore Nurse and the current approach to physical health assessment and the techniques they apply in their practice, we decided to conduct this research.

\section{Objective of the Study}

To assess the knowledge, attitude and practice of nurses related to physical assessment of severely sick patients in the intensive care unit at Tertiary Care Hospital in Lahore, Pakistan.

\section{Operational Definitions}

\section{Physical Assessment}

Evaluation of body system from head to toe for critically sick patients in the intensive care unit.

\section{Knowledge of Physical assessment}

The Knowledge of nurses toward Physical examination measured by quiz Questionnaire.

\section{Attitude of Physical assessment}

It indicates that belief of nurses toward physical examination on critically sick patients.

\section{Practice of physical assessment}

It referred to the level of nurses' ability in making skill of practice accurately and timely in the intensive care unit admitted patients.

\section{Research Hypothesis}

\section{Null Hypothesis}

They have no knowledge, attitude, and practice towards physical assessment working in the intensive care unit at Tertiary Care Hospital Lahore.

\section{Alternative Hypothesis}

$>$ They have knowledge, attitude, and practice towards physical assessment working in the intensive care unit at Tertiary Care Hospital Lahore. 
International Journal of Health, Medicine and Nursing Practice

ISSN 2710-1150 (Online)

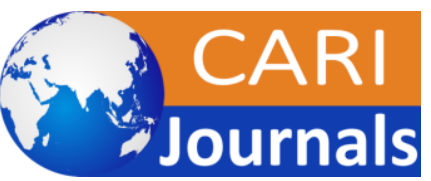

Vol. 3, Issue No. 1, pp 44- 61, 2021

Www.carijournals.org

\section{Study Variables}

Knowledge, Attitude and Practice of nurses toward physical assessment of critically sick patients

Age and sex of respondents

Education level, marital status and Monthly incomes

Experience in intensive care unit work and Training

\section{Significance of the Study}

Critically ill patients need a state-of-the-art approach that depends on the individual's physical diagnosis. Cognitive skills and experienced practice with positive behaviors to guide the search for a physical examination based on a nursing action plan. Therefore, to assess the knowledge, nursing attitude regarding physical examination of critically sick patients utilized to enhance the standard care of patients in the intensive care unit. However, to identify the difference in cognitive and practical abilities between nurses who perform physical examinations of critically sick patients. To improve the attitude of nurses towards handling the patients in the intensive care unit. The study's findings will encourage nurses to perform routine bedside physical examinations in the intensive care unit. This article will be used for the peer review online website. The results of the study will be used as a baseline and reference for other studies.

\section{LITERATURE REVIEW}

\section{Theoretical Review}

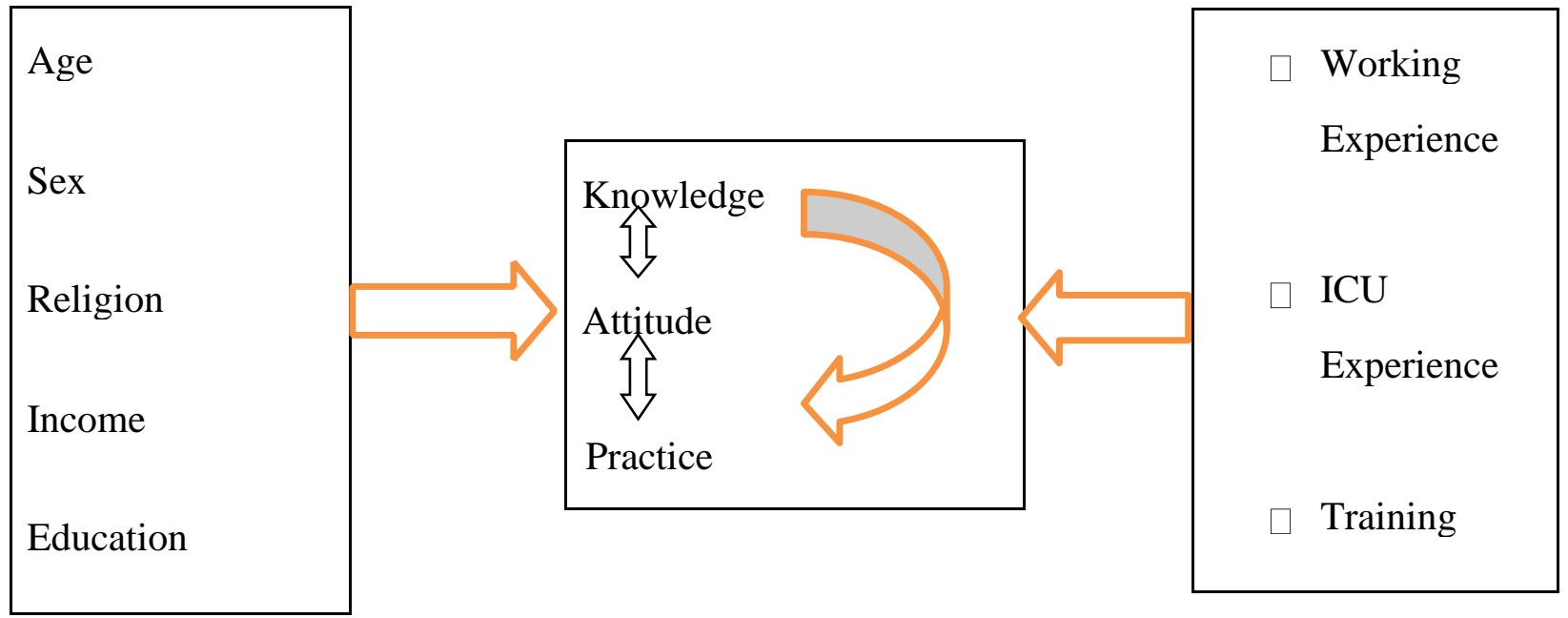

\section{Figure 1: Conceptual Frame Work Logical Model}

A review of the various literatures shows that working experience, intensive care unit experience, age and gender, and the level of education of the individual affect the nurses of intensive care unit. Practice skills are related to the knowledge of intensive care unit nurses. The attitude of intensive care unit nurses also influences the potential skills and knowledge level of the practice (Khoran, Alhani \& Hajizadeh, 2018). 
International Journal of Health, Medicine and Nursing Practice

ISSN 2710-1150 (Online)

Vol. 3, Issue No. 1, pp 44- 61, 2021

$\underline{\text { www.carijournals.org }}$

\section{Empirical Review}

Physical assessment skills are an important part of nursing practice. During a shift nurses almost four times examine the patient from head to toe. The importance and frequency of this procedure has led to controversy over the determination of the important components of the assessment to ensure procedure preparedness (Fusner, Moots, O'Brien, \& Sinnott, 2020). Nurses need to have sufficient knowledge, skills and critical thinking skills to provide competent and effective care. Intensive care unit (ICU) is a main component and the heart of a clinical care setting. Due to the emergency situation of hospitalized patients remained in the Intensive Care Unit. Critical care nurses require excellent professional knowledge and experience, general medical qualifications, and great expertise in working with modern equipment. In Intensive care units, high-standard critical care, advanced equipment, intensive care unit staff, and efficient group decisions facilitate patient rehabilitation (Esfandani, Aliyari, Pishgooei, \& Ebadi, 2017).

The intensive care unit nurses examines all attached devices, surgical incision marks and access points in the patient's physical examination, not only the patient's body but also the patient's monitoring machine, ventilator machine and telemetry, the family on the edge of the bed. And presence, presence or absence, their mood and consultation. The assessment of a critically sick patient and family begins when a nurse notifies the admission of patient and continues to the next stage of care. Criticism is a consistent and systematic way to diagnose a patient and his family without the key to developing the ability to criticize. It will be easy to lose on precision or details that could point to a real or potential problem that also reflects the patient's changing condition (Liyew, Dejen Tilahun, Kassew, \& Practice, 2020). Sometimes, the nursing examination can help to identify a medical diagnosis. Nursing diagnosis individually focuses on the patient's response to real or possible concerns. Diagnosis should focus on the patient first, then on the technology. Criticism of the patient with technology that promotes information obtained directly from the diagnosis must be the focus of the practicing caregiver (Alamri \& Almazan, 2018).

Skilled and knowledgeable critical care staff is an important part of providing high quality care in critical situation. Critical care staff, especially nurses, need to handle unexpected emergencies and, as such, they need appropriate skills and professional knowledge. Another study found that more and more experienced nurses used less academic knowledge. In simple words, the use of academic knowledge was negatively linked to work experience (Noroozi \& Moshri, 2009). Health assessment forms a key component in a nurse's expertise and acts as a crucial role to find out difficulties in the development of patients' different systems and nursing care plans. Nurses' ability to make medical decisions can affect the standard of care more than any other factor, and that ability relies on a number of skills, as well as health screening. The nurses who have advanced diagnostic skills, advanced learning skills and interested in using technology are the most successful nurses (Khoran, Alhani, Hajizadeh, et al., 2018).

Some literature suggests that experienced nurses have more knowledge about physical assessment techniques. Physical diagnostic techniques were mentioned as the maximum difference performed by nurses with low experience in the nursing profession. Evidence-based practices in nursing are professional responsibilities not only a duty and practice. Nurses can improve the clinical practice, 
International Journal of Health, Medicine and Nursing Practice ISSN 2710-1150 (Online)

Vol. 3, Issue No. 1, pp 44- 61, 2021

$\underline{\text { www.carijournals.org }}$

standard and effectiveness of nursing care services by using evidence-based practices (Esfandani et al., 2017). Nurses have historically amazed the medical profession by examining patients. Although expert observation has provided explanations and justifications for the practice of nurses, the extent to which knowledge and skills are appropriate for physical examination by nurses has been discussed many times. Modern theories suggest that this problem has not been resolved, and concerns remain about the accuracy of the physical assessment of nursing professionals (Douglas, Windsor, Lewis, \& Sciences, 2015). Nursing reviews are necessary to the quality and evidence of deceased care. The issues identified to provide a basis for age care services and managers to ensure that nurses are prepared to perform appropriate and required assessments for the provision of appropriate possible care, training and ongoing support can be obtained (Weber \& Kelley, 2013).

Systematic physical examination should be taught and the inclusion of routine clinical practice in nursing and medicine is discussed. Although the physical system approach provides a basis for physical assessment, the traditional comprehensive head-to-toe test list (nursing textbooks include more than 120 skills as usual) is not practically viable. And it is criticized for its medical relevance or lack of consideration of context. (Douglas et al., 2016). A study conducted in Italy states that 'overall skin color examination', 'assessment of breathing efforts',' asses level of consciousness and mental status', 'examination of wounds', 'Extremities Assessment for Skin Color, contour and Hair Growth, 'Assessment of Speech' and 'Facial Assessment for Movement and Thrill' Exercise while examining parasitic and capillary refill ',' Eliminate intensity for relaxation ',' Assess 'muscle strength', 'Examine muscle and intensity for size and balance', 'Equal, round pupils', 'Glasgow Coma Scale Estimation', 'Accommodation and Reactive to light' are rarely performed. However, 'Auscultation of Lungs Sounds', 'Auscultation of Heart Sounds', 'Abdominal Auscultation for Intestinal Sounds' and 'Spinal Examination' are rarely performed by more than $60 \%$ of the study participants and they were not considered part of general nursing practice (Cicolini et al., 2015).

Numerous research studies on physical assessment techniques have shown that one-third of the physical examination techniques taught in basic nursing education courses are regularly implemented in clinical area (Cicolini et al., 2015). In critically ill patients, more than one traumatic symptom was common in the intensive care unit, often at critical levels. Traditionally, performing a physical assessment and obtaining health history from clients in many regions is generally considered a medical role rather than a nursing role. However, a health assessment provides an approach for nurses to base their nursing care plan. This gives them the opportunity to develop a professional treatment regimen to provide complete nursing care with their clients. Thus, the nurse's ability to identify both normal and abnormal physical outcomes increases the nurse's self-confidence and enhances the client's health outcomes (Kutah, 2021).

\section{METHODOLOGY}

Study Design: A cross-sectional study was conducted.

Settings: Intensive Care Units in Tertiary Care Hospital, Lahore

Duration of Study: From February 2021 to May 2021

Sample Size: Population was 200 in ICU and data collected from 138 nurses. Sample size was calculated by the "World Health Organization" online sample size calculator. The estimated 
population mean 9.93, confidence level $95 \%$, absolute precision required 0.50 , population standard deviation 2.99, population variance 8.9401. Twelve added to the sample size $(n=138)$ to overcome non-response and failure to follow-up.

\section{Estimating a Sample Size}

$$
\mathbf{n}=\underline{\mathbf{Z}^{2} \mathbf{a} / 2} \frac{\mathbf{a}^{2}}{\mathbf{d}^{2}}
$$

$\mathbf{Z}_{\mathbf{a} / 2 .}$ (Divide the confidence interval by two (2), and look at this area in $\mathrm{Z}$ table):

$$
0.95
$$$$
\text { I }
$$

the closest $\mathrm{z}$-score for 0.475 is 1.96 .

$$
\begin{aligned}
& \mathrm{a}^{2}=8.9401 \\
& \mathrm{~d}=0.50 \\
& \mathrm{n}=\frac{(1.96)^{2} 8.9401}{(0.50)^{2}} \\
& \mathrm{n}=\frac{3.8416 \times 8.9401}{0.25} \\
& \mathrm{n}=\frac{34.34429}{0.25} \\
& \mathbf{n}=\mathbf{1 3 8}
\end{aligned}
$$

\section{Sampling Technique}

Convenience sampling methods was used to collect data.

\section{Inclusion Criteria}

The inclusion criteria include all nurses who were working in the intensive care unit and were present at the time of data collection having experience of at least six months at Tertiary Care Hospital, Lahore and willing to participate.

\section{Exclusion Criteria}

The exclusion criteria for this study are that the nurses who are not directly involved in management of the patients (e.g., nursing managers, nursing supervisors and tutorial staffs) were excluded.

\section{Data Collection Procedure}

Data was collected through structured questionnaires in Tertiary Care Hospital, Lahore. Participants were asked to sign a consent form before filling out the questionnaire. During data collection, the supervisor checked the questionnaires regularly. A questionnaire was given to the nurses who are willing to participate. Voluntary participation by participants without any 
International Journal of Health, Medicine and Nursing Practice ISSN 2710-1150 (Online)

Vol. 3, Issue No. 1, pp 44- 61, 2021

$\underline{\text { www.carijournals.org }}$

concessions or privileges. The researcher was asked the participants to complete the questionnaire within thirty minutes so that they could not use the internet and other resources to answer scientific questions. The researcher's interventions were applied to explain the difficulties faced by the participant in understanding the applicants' questions.

The questionnaire used in this study was taken from the study by Nigussie. The questionnaire consists of four parts which were the data features, knowledge, attitude, and practices of the nurses working in the intensive care unit about the physical examination of patients.

Section 1: Demographic characteristics of the study participants were included

Section 2: Nurses' knowledge of physical examination of critically ill patients was observed that contains 15 multiple-choice questions. The correct/right answer was coded as 1 and the incorrect/wrong answer was coded as 0 . The probable range of entire knowledge points on physical assessment was 0-15. Nurses who come in 0 have poor knowledge and about 15 possible have good knowledge.

Section 3: Through a questionnaire that contains 10 items, the nurses' attitude towards physical evaluation was measured. Positively coded items was five $(1=$ strongly $5=$ strongly agree $)$ and negatively coded were the next five ( $5=1=$ strongly agree). Therefore, the feasible score range was 10 to 50. Nurses with a score of nearly fifty which identify appreciative attitude and participant with a score of nearly ten indicate extremely inferior attitude towards physical examination skills.

Section 4: Physical examination was measured through the Nurses' Practices Questionnaire, which included 30 items. The total score of physical exam practice is 30-180 which has changed to percentage. Measure each skill using the Likert scale. There are only six options available for one choice: $0=$ I don't know how to do this technique, $1=\mathrm{I}$ know how to do this technique, but it's not part of my medical procedure, $2=\mathrm{I}$ rarely do this technique (a few times), $3=\mathrm{I}$ do this technique occasionally (a few times in a year), $4=\mathrm{I}$ do this technique in my medical practice (every 2-5 times) I do this technique frequently, $5=\mathrm{I}$ do this technique regularly in my clinic practices (whenever I work).

\section{Data Analysis Procedure}

The statistical package for social sciences (SPSS) version 25 was used for data analysis. Pearson correlation test was performed to find out the correlation between knowledge with attitude and knowledge with practice. Identification numbers were given to the questionnaires for counting and management purposes. All answers were coded with numbers and then put into a statistical package for social sciences for data analysis. For the analysis, of the demographic data descriptive statistics were used, to measures standard deviation, frequencies and percentages. The results displayed in tables and charts. 
International Journal of Health, Medicine and Nursing Practice ISSN 2710-1150 (Online)

Vol. 3, Issue No. 1, pp 44- 61, 2021

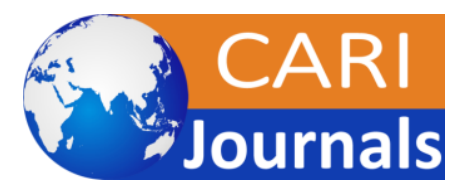

Www.carijournals.org

\section{FINDINGS AND PRESENTATIONS}

\section{Demographic Characteristic}

Data was collected from 150 nurses from whom 12 participants were failed to complete the questionnaire. All participants were females. The 44(31.9\%) participants married and 94(68.1\%) were unmarried. The education status of study respondents were 56(40.6) diploma holders in general nursing, about 63(45.7\%) were BSN degree holders and around 19(16.8\%) were masters. Most of the respondents $123(89.1 \%)$ were taken training and only $15(10.9 \%)$ study respondents were not taken training regarding physical examination (Table 1).

\section{Table 1: Demographic Characteristics}

\begin{tabular}{lllcc}
\hline S/No. & Variables & Categories & Frequency $(\boldsymbol{f})$ & Percentage $\%$ \\
\hline 1 & Sex & Female & 138 & 100 \\
2 & Marital status & Married & 44 & 31.9 \\
& & Unmarried & 94 & 68.1 \\
3 & Religion & Muslim & 70 & 50.7 \\
& & Christian & 68 & 49.3 \\
4 & Education level & Diploma & 56 & 40.6 \\
& & Degree & 63 & 45.7 \\
& \multirow{2}{*}{5} & Master & 19 & 16.8 \\
& Work area currently & Adult Intensive Care Unit & 138 & 100 \\
& employed & & & \\
6 & Training & Yes & 123 & 89.1 \\
& & No & 15 & 10.9 \\
\hline
\end{tabular}

Knowledge Regarding Physical Assessment

The study respondents $82(59.4 \%)$ out of 138 were response incorrect answer on respiratory rate assessment. Only $48(34.8 \%)$ study respondents react correctly to bruits presence in the carotid artery. Most of the respondents 97(70.3) knows the normal breathing sounds. The 54(39.1) out 138 respondents understand where the S3 heart sound heard. The 87(63.0) respondents react correctly on breast tissues does not change with aging. Pitting edema that disappears within a few seconds correct answered by 81(58.7) of the study participants. Most of the participants 76(55.0\%) response correct on which involves stage 3 pressure ulcer injuries. Only 52(37.7) out of 138 study respondents were correctly answered on normal body temperature varies throughout the day. The 80(58.0) correctly answered blood pressure in the left and right arm differs by more than $15 \mathrm{mmHg}$. Most of the participants 87(63.0) were knows the most common sign and symptom of respiratory dysfunction. The 86(62.3) out of 138 respondents were correctly answer the definition of orthopnea. The 88(63.8) respondents were incorrectly answered on does addition breathing sound like wheeze and stridor are common. Only 49(35.5) participants knows the additional information related to this recent development. About 81(58.7) of respondents correctly answered the complications of the aortic aneurism. Around 46(33.3) were correctly answered the mismatched about normal breathing sound with location (Table 2). 
International Journal of Health, Medicine and Nursing Practice ISSN 2710-1150 (Online)

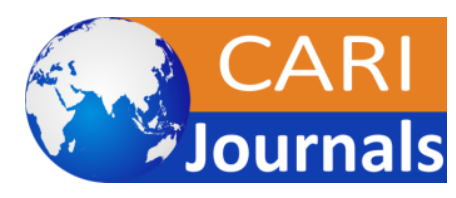

Vol. 3, Issue No. 1, pp 44- 61, 2021

Www.carijournals.org

Table 2: Knowledge of Study Participants Regarding Physical Assessment

\begin{tabular}{|c|c|c|c|}
\hline Sr/No. & Knowledge items & $\frac{\text { Correct Answer }}{f(\%)}$ & $\frac{\text { Incorrect Answer }}{f(\%)}$ \\
\hline 1 & Respiratory Rate & $56(40.6)$ & $82(59.4)$ \\
\hline 2 & The presence of bruits & $48(34.8)$ & $90(65.2)$ \\
\hline 3 & Normal breathing sound & $97(70.3)$ & $41(29.7)$ \\
\hline 4 & S3 heart sound & $54(39.1)$ & $84(60.9)$ \\
\hline 5 & Breast tissue does not change with aging & $87(63.0)$ & $51(37.0)$ \\
\hline 6 & Pitting edema & $81(58.7)$ & $57(41.3)$ \\
\hline 7 & Stage 3 pressure ulcer & $76(55.0)$ & $62(44.9)$ \\
\hline 8 & $\begin{array}{l}\text { Normal body temperature varies throughout } \\
\text { the day }\end{array}$ & $52(37.7)$ & $86(62.3)$ \\
\hline 9 & $\begin{array}{l}\text { Usually, blood pressure differs by more } \\
\text { than } 15 \mathrm{mmHg}\end{array}$ & $80(58.0)$ & $58(42.0)$ \\
\hline 10 & $\begin{array}{l}\text { The common sign and symptom of } \\
\text { respiratory dysfunction is }\end{array}$ & $87(63.0)$ & $51(37.0)$ \\
\hline 11 & The definition of orthopnea & $86(62.3)$ & $52(37.7)$ \\
\hline 12 & $\begin{array}{l}\text { Does addition breathing sound like wheeze } \\
\text { and stridor are common }\end{array}$ & $50(36.2)$ & $88(63.8)$ \\
\hline 13 & $\begin{array}{l}\text { Additional information related to this recent } \\
\text { development? }\end{array}$ & $49(35.5)$ & $89(64.5)$ \\
\hline 14 & $\begin{array}{l}\text { Complications will happen for (aortic } \\
\text { aneurism)? }\end{array}$ & $81(58.7)$ & $57(41.3)$ \\
\hline 15 & $\begin{array}{l}\text { Which one is mismatched about normal } \\
\text { breathing sound with location? }\end{array}$ & $46(33.3)$ & $92(66.7)$ \\
\hline
\end{tabular}

\section{Attitude Regarding Physical Assessment}

(Table 3) shows most of the participants 84(60.9) agree that Head-to-toe physical examination is important. About 79(57.2) of the study respondents were disagree that on mechanical ventilation physical examination is a difficulty. The 83(60.1) out of 138 respondents were disagree that physical assessment always performed by a physician. Around 77(55.8) of the participants were disagree that routine physical examination is the responsibility of nurses. Most of the participants 85(61.6) agree that physical examination result in new diagnosis, may change diagnosis and treatments. About 109(79.0) disagree that physical assessment is not nursing jobs. The 96(69.6) respondents were disagree that critically ill patients have less outcome, then daily physical examination is unnecessary. Only 50(36.2) of study participants agree that physical assessment take a long time. Most of the participants 96(69.6) disagree that in intensive care unit work overload, physical examination is not more necessary. Around 104(75.4) of the study respondents disagree that always physical examination is not more important. 
International Journal of Health, Medicine and Nursing Practice ISSN 2710-1150 (Online)

Vol. 3, Issue No. 1, pp 44- 61, 2021

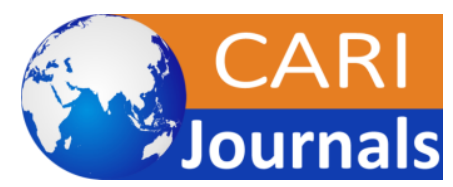

WwW.carijournals.org

Table 3: Attitude of Study Respondent's Regarding Physical Assessment

\begin{tabular}{|c|c|c|c|}
\hline S/No & Attitude related items & Agree $f(\%)$ & Disagree $f(\%)$ \\
\hline 1 & Head-to-toe physical examination & $54(39.1)$ & $84(60.9)$ \\
\hline 2 & $\begin{array}{l}\text { Mechanical ventilation physical examination is a } \\
\text { difficulty }\end{array}$ & $79(57.2)$ & $59(42.8)$ \\
\hline 3 & Physical assessment always performed by a physician & $83(60.1)$ & $55(39.9)$ \\
\hline 4 & $\begin{array}{l}\text { Routine physical examination is the responsibility of } \\
\text { nurses }\end{array}$ & $77(55.8)$ & $61(44.2)$ \\
\hline 5 & New diagnosis, may change diagnosis and treatments & $53(38.4)$ & $85(61.6)$ \\
\hline 6 & Physical assessment is not nursing jobs & 109(79.0) & $29(21.0)$ \\
\hline 7 & $\begin{array}{l}\text { Critically ill patients have less outcome, then daily } \\
\text { physical examination is unnecessary }\end{array}$ & $96(69.6)$ & $42(30.4)$ \\
\hline 8 & Physical assessment take a long time & $88(63.8)$ & $50(36.2)$ \\
\hline 9 & Work overload, physical examination is not necessary & $96(69.6)$ & $42(30.4)$ \\
\hline 10 & Always physical examination is not more important & $104(75.4)$ & $34(24.6)$ \\
\hline
\end{tabular}

\section{Practices Regarding Physical Assessment}

(Table 4) shows practice of study respondents regarding physical examination of critical ill patients. The 39(28.3) of the study participants regular, 73(52.9) sometimes, 26(18.8) never inspect eyes and hair growth of critical ill patients. Most of the respondents 87(63.0) were regular assess for pupils. About 86(62.3) participants regular inspect the oral cavity. Around 87(63.0) respondents were sometimes inspect the chest shape. Only 41(29.7) out of 138 were regular inspect genital area. The 84(60.9) of the study respondents regular inspect extremities. Only 20(14.5) were never inspect muscles and limp. 76(55.1) participants were sometimes inspect the spine. Most of the 85(61.6) study participants were regular inspect skin lesions \& wounds. The 18(13.0) participants never inspect skin integrity and color. About 82(59.4) respondents were regular inspect and palpate edema. Around 71(51.4) participants regular observe range of motion of joints. Only 7(5.1) participants were never inspect face movement and sensation. Most of the 99(71.7) study respondents were regular evaluate breathing effort. The 84(60.9) respondents were regular assess mental status and Glasgow Coma Scale. About 76(55.1) were regular palpate and inspect capillary refill. Only 4(2.9) participants were never palpate distal pulses for circulation. The 85(61.6) of the study participants were regular auscultate lung sounds. The 11(8.0) study respondents were never auscultate heart sounds, 10(7.2) never assess hearing. About 87(63.0) of the study participants sometimes palpate extremities for tenderness, 86(62.3) were sometimes assess muscle strength, 74(53.6) were sometimes evaluate speech. Around 81(58.7) study participants were regular auscultate bowel sounds, 83(60.1) were regular palpate abdominal tenderness \& distension, 106(76.8) were regular measure body temperature, 108(78.3) were regular measure SPO2, 94(86.1) were regular measure NGT and monitory machines, 92(66.7) were regular measure Blood Pressure. 
International Journal of Health, Medicine and Nursing Practice ISSN 2710-1150 (Online)

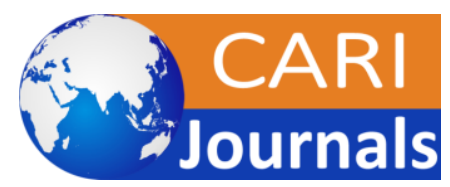

Vol. 3, Issue No. 1, pp 44- 61, 2021

Www.carijournals.org

Table 4: Practices of Study Respondents Regarding Physical Assessment

\begin{tabular}{|c|c|c|c|c|}
\hline \multirow[t]{2}{*}{ S/No } & \multirow[t]{2}{*}{ Variables } & \multicolumn{3}{|c|}{ Response } \\
\hline & & $\begin{array}{c}\text { Never } \\
\text { Perform } \\
f(\%)\end{array}$ & $\begin{array}{c}\text { Sometimes } \\
\text { Perform } \\
f(\%)\end{array}$ & $\begin{array}{c}\text { Regular } \\
\text { Perform } \\
f(\%)\end{array}$ \\
\hline 1 & Inspect eyes and hair growth & $26(18.8)$ & $73(52.9)$ & $39(28.3)$ \\
\hline 2 & Assess for Pupils & $16(11.6)$ & $35(25.4)$ & $87(63.0)$ \\
\hline 3 & Inspect the oral cavity & $8(5.8)$ & $44(31.9)$ & $86(62.3)$ \\
\hline 4 & Inspect chest shape & $29(21.0)$ & $87(63.0)$ & $22(15.9)$ \\
\hline 5 & Inspect abdomen & $18(13.0)$ & $41(29.7)$ & $79(57.2)$ \\
\hline 6 & Inspect genital area & $20(14.5)$ & $77(55.8)$ & $41(29.7)$ \\
\hline 7 & Inspect extremities & $18(13.0)$ & $36(26.1)$ & $84(60.9)$ \\
\hline 8 & Inspect muscles and limp & $20(14.5)$ & $75(54.3)$ & $43(31.2)$ \\
\hline 9 & Inspect the spine & $25(18.1)$ & $76(55.1)$ & $37(26.8)$ \\
\hline 10 & Inspect skin lesions \& wounds & $25(18.1)$ & $28(20.3)$ & $85(61.6)$ \\
\hline 11 & Inspect skin integrity \& color & $22(15.9)$ & $42(30.4)$ & $74(53.6)$ \\
\hline 12 & Inspect and palpate edema & $18(13.0)$ & $38(27.5)$ & $82(59.4)$ \\
\hline 13 & Observe range of motion of joints & $12(8.7)$ & $55(39.9)$ & $71(51.4)$ \\
\hline 14 & Face movement and sensation & $7(5.1)$ & $40(29.0)$ & $91(65.9)$ \\
\hline 15 & Evaluate breathing effort & $6(4.3)$ & $33(23.9)$ & $99(71.7)$ \\
\hline 16 & $\begin{array}{l}\text { Mental status and Glasgow Coma } \\
\text { Scale }\end{array}$ & $12(8.7)$ & $42(30.4)$ & $84(60.9)$ \\
\hline 17 & Palpate and inspect capillary refill & $9(6.5)$ & $53(38.4)$ & $76(55.1)$ \\
\hline 18 & $\begin{array}{l}\text { Palpate distal pulses for } \\
\text { circulation }\end{array}$ & $4(2.9)$ & $46(33.3)$ & $88(63.8)$ \\
\hline 19 & Auscultate lung sounds & $6(4.3)$ & $47(34.1)$ & $85(61.6)$ \\
\hline 20 & Auscultate heart sounds & $11(8.0)$ & $55(39.9)$ & $72(52.2)$ \\
\hline 21 & Bowel sounds & $1(0.7)$ & $56(40.6)$ & $81(58.7)$ \\
\hline 22 & tenderness \& & $7(5.1)$ & $48(34.8)$ & $83(60.1)$ \\
\hline 23 & Palpate extremities for tenderness & $8(5.8)$ & $87(63.0)$ & $43(31.2)$ \\
\hline 24 & Assess muscle strength & $15(10.9)$ & $86(62.3)$ & $37(26.8)$ \\
\hline 25 & Evaluate speech & $14(10.1)$ & $74(53.6)$ & $50(36.2)$ \\
\hline 26 & Assess hearing & $10(7.2)$ & $83(60.1)$ & $45(32.6)$ \\
\hline 27 & Measure Blood Pressure & $5(3.6)$ & $41(29.7)$ & $92(66.7)$ \\
\hline 28 & Measure body temperature & $5(3.6)$ & $27(19.6)$ & $106(76.8)$ \\
\hline 29 & Measure SPO2 & $0(0.0)$ & $30(21.7)$ & $108(78.3)$ \\
\hline 30 & NGT and monitory machines & $10(7.2)$ & $34(24.6)$ & $94(86.1)$ \\
\hline
\end{tabular}


International Journal of Health, Medicine and Nursing Practice ISSN 2710-1150 (Online)

Vol. 3, Issue No. 1, pp 44- 61, 2021

$\underline{\text { www.carijournals.org }}$

\section{Correlation of Knowledge with Attitude}

The correlation between knowledge and attitude of intensive care nurses towards physical assessment of critical ill patients were significant $0.34 \%$ (Table \#05).

Table 5: Correlation of Knowledge with Attitude Items

\begin{tabular}{llrr}
\hline & & Knowledge type & Attitude type \\
\hline Knowledge & Pearson Correlation & 1 & $.181^{*}$ \\
type & Sig. (2-tailed) & & .034 \\
& $\mathrm{~N}$ & 138 & 138 \\
Attitude type & Pearson Correlation & $.181^{*}$ & 1 \\
& Sig. (2-tailed) & .034 & \\
& $\mathrm{~N}$ & 138 & 138 \\
\hline
\end{tabular}

\section{Correlation of Knowledge with Practice}

The correlation between knowledge and practice of intensive care nurses towards physical assessment of critical ill patients were significant $0.32 \%$ (Table \#06).

Table 6: Correlation of Knowledge with Practice Items

\begin{tabular}{llrr}
\hline & & Knowledge type & Practice type \\
\hline Knowledge & Pearson Correlation & 1 & $-.183^{*}$ \\
type & Sig. (2-tailed) & & .032 \\
& $\mathrm{~N}$ & 138 & 138 \\
Practice type & Pearson Correlation & $-.183^{*}$ & 1 \\
& Sig. (2-tailed) & .032 & \\
& $\mathrm{~N}$ & 138 & 138 \\
\hline
\end{tabular}

\section{DISCUSSION, CONCLUSION AND RECOMMENDATIONS}

\section{Discussion of Findings}

The study was carried out to assess the knowledge, attitude, and practice among intensive care unit nurses towards physical assessment of critically sick patients in Tertiary Care Hospital Lahore, Pakistan. In this study, 138 respondents fulfill the investigator principles. Around $57.2 \%$ of nurses had good knowledge, $59.4 \%$ positive attitude, and $68.1 \%$ good practice towards critical ill patient's physical assessment. Similarly, in the study conducted by (Liyew, Dejen Tilahun, \& Kassew, 2020) the findings showed that the nurses working in ( ICU ) intensive care unit were wellinformed and had a favorable attitude for physical assessment in critically sick patients. (Liyew, Dejen Tilahun, \& Kassew, 2020). On the other hand, in a study conducted by (Nigussie, 2018), $49.7 \%, 62.9 \%$ and close to $43.7 \%$ of intensive care unit nurses, respondents to the study had little knowledge about the physical assessment, negative attitudes and poor practice respectively toward physical assessment for critically ill patients (Nigussie, 2018).

The attitude of the intensive care unit nurses for physical examination of critically ill patients was $59.4 \%$. Of the study participants, approximately 82 people had a record higher than mean called a positive attitude, while $56(40.6 \%)$ was considered a negative attitude towards the physical 
International Journal of Health, Medicine and Nursing Practice ISSN 2710-1150 (Online)

Vol. 3, Issue No. 1, pp 44- 61, 2021

$\underline{\text { www.carijournals.org }}$

examination of critically ill patients (Figure \#03). Our study found that physical assessment through the perceived positive attitude of the nurse is related to good practice skills. A similar study by Thiel and Ghosh reported that although nurses had a positive attitude regarding evidencebased practice (Thiel \& Ghosh, 2008). However, physical assessment by nurses states that this is not part of their job, and in some nurses, negative behavior-related exercise skills, which are considered negative behaviors related to poor exercise skills (Secrest, Norwood, \& Dumont, 2005).

The study concluded that approximately $45.4 \%$ regular, sometimes $34.3 \%$ and $20.3 \%$ of respondents do not perform regular physical examinations in the intensive care unit of critically ill patients. Similarly, one study reported that only $44 \%$ and 37 skill-related respondents performed routine or regular and sometimes physical examinations. In addition, 19\% of intensive care unit nurses never make a physical assessment for critically ill patients (Nigussie, 2018). However, far from the results of our study, this study conducted in Argentina among intensive care unit nurses found that approximately $79.3 \%$ respondents never perform practical skills in the direction of physical assessment for critically ill patients (Alberto et al., 2014). The differences between these studies may be related to the level of training and other factors affect the performance of practice skills in the intensive care unit. Instead, various works of literature suggest that one-third of the procedures selected by nurses in the clinical practice area are not routinely applied (Birks et al., 2013).

The study examines the cardiovascular system, nervous system, critical symptoms, and skin lesions and lesions and extremities that are performed on a regular basis. The study, conducted in Australia, aims to identify the nurse's basic diagnostic skills used on a regular basis through observation of basic symptoms, cardiovascular abilities and neurological diagnosis skills (Osborne et al., 2015). The similarities may be due to areas that are extremely critical in emergency areas that need more attention and early detection and aggressive intervention

Our study found that study respondents with less than 10 years of work experience have better practical skills than those who are more than ten years of work experience in intensive care units. This shows that the less experienced in the service, the better the process skills. Similarly, a study in Australia found that, the use of the basic techniques of practical skills in physical examination decreased as increase the years of clinical experience. Nurses who have more than ten years of clinical experience use poor exercise skills than other groups (Osborne et al., 2015). On the other hand, in this study conducted by Nigussie, 2018, study respondents experienced less than 10 years of experience, far more than those with more than 10 years of experience working in the service. It shows less experience in service, less practice skills (Nigussie, 2018).

In this study, the results showed that degree holder nurses had better knowledge than diploma holder nurses. This is also the case with another study, which describes in detail as nurses' higher education to provide a higher level of safety of patients with advanced nursing care. Such efficient performance requires the combination of nursing knowledge and skills that can lead to strong decision making and better medical reasoning and performance (Fennessey \& Wittmann-Price, 2011).

Our study shows that more experienced nurses had less knowledge than less experienced ones. In contrast, the study found that more experienced nurses had more knowledge than less experienced 
ones. However, other studies have resulted that more experienced nurses have utilized less theoretical/academic knowledge on physical assessment (Noroozi \& Moshri, 2009). Some other literature shows that experienced nurses are more knowledgeable and strong skills about physical examination. Physical assessment skills were cited as making it more difficult for a respondent with less experience in nursing to perform. The more experienced group had more knowledge of physical diagnostic skills, the skills were used more frequently and were not difficult to use (Yanhua \& Watson, 2011).

\section{Conclusion}

Its conclusion was based on results, the good knowledge, positive attitude and good practice of intensive care unit nurses towards physical assessment of critically ill patients. There was a significant correlation between knowledge with attitude, and practice in intensive care unit among nurses. It means the knowledge of study respondents found to be as good while the attitude response was also as found to be positive perception. The skill practice of study respondents is good performance response. Physical assessment skills are permanently referred to as part of the first stage of the nursing process, but further clarification is needed on what skills are included in the definition.

\section{Recommendations}

It is recommended that better to more emphasize on the skill of practice on physical assessment in the intensive care unit at federal hospitals. The frequently giving updates training for intensive care unit nursing on physical assessment. Better to make policy and procedure on the job description for intensive care unit nurses. To assign an intensive care unit more experienced nurses very important. Better to give training for intensive care unit nurses on physical assessment. The nurses better to enhance their level of knowledge and skill of practice on physical assessment. Nurses, who had better knowledge and skill, should also teach their respective colleagues.

Therefore, this study should be repeated with a wide range of RN samples from different geographical areas and different practice environments. It is important to examine the basic physical health assessment techniques used by nurses in different medical environments, and to compare differences between the techniques used by nurses based on years of experience or educational background. The decision-making process should also be studied as to which technique should be used for physical assessment. It was a cross sectional study only it should be conducted experimental studies as well.

\section{Limitations}

The study participants were recruited using a simple sampling method that is limited to generalizing the study results.

\section{Acknowledgement}

With the name of Allah, the most Beneficent and Merciful. All respects to our last Prophet Hazrat Muhammad (S.A.W) who teaches us the ways of learning, knowledge and wisdom for all humanity. 
International Journal of Health, Medicine and Nursing Practice

ISSN 2710-1150 (Online)

Vol. 3, Issue No. 1, pp 44- 61, 2021

$\underline{\text { www.carijournals.org }}$

We since thanks to our faculty Mr. Muhammad Hussain and head of the department Mr. Muhammad Afzal and all participants who participate in this study.

\section{Declaration of Interest}

The author declared that there is no competing interest.

\section{Author Contribution}

The first author contributing to knowledge analysis, drafting the article and gave final approval of the version.

\section{Availability of Data and Material}

A Questionnaire guide is available from the corresponding author upon reasonable request.

\section{REFERENCES}

Alamri, M. S., \& Almazan, J. U. (2018). Barriers of physical assessment skills among nursing students in Arab Peninsula. International journal of health sciences, 12(3), 58.

Alberto, L., Zotárez, H., Cañete, Á. A., Niklas, J. E. B., Enriquez, J. M., Gerónimo, M. R., . . . Nursing, C. C. (2014). A description of the ICU liaison nurse role in Argentina. 30(1), 3137.

Birks, M., Cant, R., James, A., Chung, C., \& Davis, J. J. C. (2013). The use of physical assessment skills by registered nurses in Australia: issues for nursing education. 20(1), 27-33.

Cicolini, G., Tomietto, M., Simonetti, V., Comparcini, D., Flacco, M. E., Carvello, M., \& Manzoli, L. J. J. o. c. n. (2015). Physical assessment techniques performed by I talian registered nurses: A quantitative survey. 24(23-24), 3700-3706.

Douglas, C., Booker, C., Fox, R., Windsor, C., Osborne, S., \& Gardner, G. J. J. o. c. n. (2016). Nursing physical assessment for patient safety in general wards: reaching consensus on core skills. 25(13-14), 1890-1900.

Douglas, C., Windsor, C., Lewis, P. J. N., \& Sciences, H. (2015). Too much knowledge for a nurse? Use of physical assessment by final-semester nursing students. 17(4), 492-499.

Esfandani, K., Aliyari, S., Pishgooei, A. H., \& Ebadi, A. J. )2017(. و. •. م. p. و. ن. Promoting critical care nurses' information literacy through an evidence-based practice workshop: a quasiexperimental study. $10(2), 0-0$.

Fennessey, A., \& Wittmann-Price, R. A. (2011). Physical assessment: A continuing need for clarification. Paper presented at the Nursing Forum.

Fusner, S. M., Moots, H., O'Brien, T., \& Sinnott, L. T. J. N. e. (2020). Faculty perceptions of the importance of physical assessment skills taught in prelicensure nursing education. 45(5), 248-251. 
International Journal of Health, Medicine and Nursing Practice ISSN 2710-1150 (Online)

Vol. 3, Issue No. 1, pp 44- 61, 2021

$\underline{\text { www.carijournals.org }}$

Khoran, M., Alhani, F., \& Hajizadeh, E. (2018). Nurses challenges in health assessment skills in Iran and another country: an integrative review. Journal of Nursing and Midwifery Sciences, 5(1), 38.

Khoran, M., Alhani, F., Hajizadeh, E. J. J. o. N., \& Sciences, M. (2018). Nurses challenges in health assessment skills in Iran and another country: an integrative review. 5(1), 38.

Kutah, O. A. J. A. J. o. N. (2021). Physical Assessment Techniques Performed by Jordanian Registered Nurses (RNs): Survey Study. 10(1), 41-48.

Liyew, B., Dejen Tilahun, A., \& Kassew, T. (2020). Knowledge, attitude, and associated factors towards physical assessment among nurses working in intensive care units: a multicenter cross-sectional study. Critical Care Research and Practice, 2020.

Liyew, B., Dejen Tilahun, A., Kassew, T. J. C. C. R., \& Practice. (2020). Knowledge, attitude, and associated factors towards physical assessment among nurses working in intensive care units: a multicenter cross-sectional study. 2020.

Meurier, C., Brown, J., \& Crouch, A. J. V. N. f. N. H. A. (2016). Physical Assessment. 148-233.

Nigussie, D. (2018). Assessment of knowledge, attitude and practice of nurses towards physical assessment on critical ill patients in intensive care unit at selected public hospitals, Addis Ababa, Ethiopia.

Noroozi, A., \& Moshri, E. J. J. o. A. U. o. M. S. (2009). The relationship between physical and human resources in the Intensive Care Units and patients mortality rate in Hospitals of Markazi Province's: 2007. 12(2), 29-38.

Osborne, S., Douglas, C., Reid, C., Jones, L., \& Gardner, G. J. I. J. o. N. S. (2015). The primacy of vital signs-acute care nurses' and midwives' use of physical assessment skills: a cross sectional study. 52(5), 951-962.

Secrest, J. A., Norwood, B. R., \& Dumont, P. M. J. J. o. P. N. (2005). Physical assessment skills: A descriptive study of what is taught and what is practiced. 21(2), 114-118.

Tan, M. W., Lim, F. P., Siew, A., Levett-Jones, T., Chua, W. L., \& Liaw, S. Y. J. N. E. T. (2021). Why Are Physical Assessment Skills Not Practiced? A Systematic Review with Implications For Nursing Education. 104759.

Thiel, L., \& Ghosh, Y. J. W. o. E. B. N. (2008). Determining registered nurses' readiness for evidence-based practice. 5(4), 182-192.

Weber, J. R., \& Kelley, J. H. (2013). Health assessment in nursing: Lippincott Williams \& Wilkins.

Yanhua, C., \& Watson, R. J. N. e. t. (2011). A review of clinical competence assessment in nursing. $31(8), 832-836$. 